\title{
CHANGING DEMANDS OF MODERN WORK AND CONTROL
}

$\mathrm{T}$

HE breakdown by occupation of the "One per Cent Sample Tables" of the 1951 Census reveals that the number is relatively small of people whose jobs are likely to be directly affected by the advanced mechanization, automatic control methods and computer techniques which constitute what is currently known as 'automation'. A more important and pervading, if less spectacular, 'new industrial revolution' is contained in the piecemeal mechanization which has been going on for many years, and which must be given attention if the trends in modern industrial work are to be seen in true perspective. The symposium held by the Ergonomics Research Society during April 8-11 at the University of Bristol under the title of "The Changing Demands of Modern Work and Control" was deliberately aimed at covering both automation and this wider field of development in manufacturing industry and agriculture.

The opening speaker, B. H. Dyson (Hoover, Ltd.), pointed out that recent developments in industry do not depend upon any radically new principles but are significant at the present time because of the rate of change involved. Their advent has been dependent upon technological developments, enabling the attainment of uniform materials and accurate rapid measurement coupled with certain economic factors. The main restriction on progress is now likely to lie in human factors : machines have taken over many human functions, but other sources of strain and difficulty remain and may indeed be thrown into greater prominence. In former days such human difficulties were solved gradually in the course of the slow evolution of tools and techniques; to-day, however, their understanding and avoidance in advance of building expensive capital equipment are an obvious need.

Mechanization is frequently said to lessen the physical losd upon the operator but to place increased stress on intellectual functions involved in controlas one speaker felicitously put it, the operator is becoming a "mental craftsman". The papers showed clearly that both parts of this statement are only half-truths. On the physiological side, H. S. Belding (University of Pittsburg) pointed out that, although remote controls could remove operators from certain very hot working environments, maintenance men might be liable to work in even more adverse climatic conditions then before. H. Scholz (Max PlanckInstitut, Dortmund) described a number of examples in which mechanization had reduced the physical work load, together with other cases where, although mechanization had been satisfactory from an engineering point of view and at first sight also beneficial to the worker, closer inspection had shown the physical load actually to have been increased. Similar results were noted in a study by $V$. Sundberg and N. Lundgren (Stockholm) of forestry work, where effort saved by the introduction of mechanical saws and winches for dragging logs was more than offset by the heavy task of carrying the saws and cables.

Automatic control devices obviously reduce rather than increase the intellectual load upon the operator. So also in a sense do all forms of mechanization which reduce the number of physical movements he has to make because fewer actions have to be controlled. Such mechanical devices do, however, often impose other kinds of intellectual load which may be more burdensome than those they have removed. Two important examples were described of devices specifically aimed at reducing such intellectual load. One, by W. T. Singleton (Boot and Shoe Research Association, Kettering), was a control for industrial sewing machines designed after laboratory and field experiments. The other example was given by $A$. W. Bailey, who described some of the latest work on tracking with 'display quickening', a form of aiding developed at the United States Naval Research Laboratory, Washington, and of topical interest as offering a possible means of mitigating a class of difficult tasks such as that of flying helicopters.

The papers specifically bearing upon automation were all attempts, by those having knowledge of automatic plants already installed, to locate and define the essential problems of human performance connected with their operation for more precise study in the future. The fact that emphasis and views differed considerably indicates that the full nature and variety of such problems are still by no means clear. Broad surveys were made by G. C. E. Burger (Philips, Eindhoven), A. Lucas (Renault, Bellancourt) and the present writer. The first spoke from the industrial medical side, and suggested the danger of some ill health due to lack of exercise and to the minor sickness often associated with dissatisfactionin this case resulting from uncertainty following the introduction of radical changes of work methods. Lucas laid stress upon possible 'nervous strain' and upon the adverse effects of isolation when there are only a few operators in a large shop, although he pointed out that no definite evidence existed upon either of these points.

Most speakers on automation came to either the overt or the tacit conclusion that although the wartime and post-war Service work on such problems as vigilance and dial reading may be of some significance for the design of work and equipment in automatic plants, there are other factors of greater importance which are as yet little studied, and which will require fundamental research before the practical problems associated with them can be solved. One of the principal of these was discussed by E. R. F. W. Crossman (University of Reading), who pointed out that process workers on existing plants are usually able, by knowledge gained from experience, to operate them with substantially greater efficiency than would otherwise be possible. He suggested that although such process work has usually been regarded as unskilled, the application of such know. ledge does represent " $a$ specific skill based on intuitive knowledge of the statistical structure of the display provided by the process and of the interaction between controls and display". This specific skill cannot be formally taught, and although it implies that the operator has in mind some rudimentary conceptual 'model' of the process he is controlling, it does not depend on accurate conceptual knowledge.

As reminders that it is difficult to apply automatic methods economically to certain processes, especially 
assembly, inspection and moderately heavy lifting, were papers by R. McKenzie (University of Edinburgh) showing how greatly performance of inspection work can be improved by suitable training, and by R. J. Whitney (University of Oxford) indicating that lifting force depends more upon the possibility of balancing the weight to be lifted with the weight of the body than upon sheer muscular power.

Viewing the papers as a whole, one can see that the application of anatomy, physiology and experimental psychology to practical problems of human work has reached a critical stage. During the later 1940's success had been achieved with Service problems and ideas of possible industrial application were being formulated. Now world-wide interest has been aroused, concrete examples of industrial application are beginning to emerge, and the approach seems likely to become established as an essential part of work- and equipment-design. For it to do so fully, however, much further research will be needed both in industry itself and in the laboratory. In this connexion two sessions a little away from the main lines of the conference were timely. The first was a discussion opened by R. G. Stansfield (Department of Industrial and Scientific Research) on the moral responsibilities of the research worker in industry, especially in cases when it is necessary for the true nature of the investigation to be disguised if the results are to be unbiased: stress was laid on the need to give full information to representatives of the work-people concerned, and to preserve secrecy of data about individuals. At the second session an account was given by R. M. W. Lund and R. Trumbull (Office of Naval Research, Washington) of the means employed by the United States Navy to sponsor its very large physiological and psychological research programmes. The realistic appraisal of the needs and motives of research workers, and the recognition of the place of fundamental research in relation to applied problems revealed in these statements, makes understandable the substantial volume of high-quality work which has emerged.

While the methods of sponsoring research are obviously important, a limiting factor in the imme. diate future is likely to lie in the obtaining of suitable research workers and in their attitude to their work. Looking back to the war years it is clear that the success achieved then in what has now become known as 'ergonomics' was due to two factors: first, an analytical approach to complex problems coupled with careful measurement, and secondly, the wide theoretical background brought by the research workers from their own disciplines. Since that time the former seems to have been well maintained, but both are equally important and for the preservation of the latter there are two constant needs. The first is to recognize that applicable results usually follow a long period of research development. The second is to maintain a climate of opinion in which a young man engaged in the human biological sciences can feel that serious attempts to tackle certain applied problems will improve rather than impair his chances of academic advancement, and will certainly enrich the ideas he brings to the fundamental problems of his own subject.

The conference was attended by some ninety-five members and visitors of whom twenty-one came from eight countries abroad. The chair at the opening session was taken by Sir Philip Morris, vice-chancellor of the University of Bristol.

\section{DEVELOPMENTAL PROCESSES IN ANIMALS}

7 HE third in the series of international scientific meetings sponsored by the Editorial Board of the Journal of Embryology and Experimental Morphology was held in Cambridge during April 10-13. Some one hundred and fifty biologists from sixteen countries took part, and only the failure of the expected Russian participants to arrive gave any ground for disappointment at the international representation at the conference.

It is probably true to say that the session devoted to demonstrations of research material, at which more than forty lines of work were displayed, provided the most comprehensive survey of present trends in developmental biology. None the less the main business of the conference was conducted in the sessions at which papers were read, and in them many of the major interests of contemporary embryology were presented for discussion.

The recrudescence of concern with the problems of neural induction in vertebrates was very evident. Thus Dr. P. D. Nieuwkoop (Utrecht) produced evidence, from explantation experiments, for believing that the amphibian neural crest is determined by a double process, an initial activation being succeeded by a transforming influence from the underlying mesoderm. He pointed out that the anterior, transverse, part of the neural fold of the neurula normally lies in front of the pre-chordal mesoderm and is underlain by endoderm. It does not give rise to neural crest derivatives in normogenesis or when cultured with ectoderm alone, but they may be formed from its cells if it is cultured in the presence of mesoderm.

Prof. T. Yamada (Nagoya) has inade important progress in the effort to isolate the components of guines pig liver and kidney responsible for their regionally specific inductive effects upon competent amphibian ectoderm. His results point very strongly to the protein part of pentose nucleoproteins as the active fraction, though it has not been possible to exclude with certainty the lipids or pentose nucleic acid itself. Heat treatment of alcohol-killed bonemarrow progressively changes the regional character of the structures it will induce. Unheated, it is a specific inducer of mesodermal structures, but after heat treatment (by steaming), first spinal and then, with increase in the duration of treatment, hind brain and finally fore brain inductions are obtained. This sequence is also the spatial sequence of the presumptive territories of these tissues in the blastula.

Miss M. Brice (Brussels) reported on the consequences of dividing urodele blastulm and young gastrulæ into two by ligature. Contrary to our earlier beliefs, an isolated ventral half-embryo may sometimes form a centre of invagination and later an embryonic axis. The formation of such secondary 'dorsal lips' appears to be associated with the local trauma involved in ligaturing. Where embryos are formed their polarity and symmetry may be reversed. In the young gastrula it is still possible to obtain a new marginal zone, nor can the symmetry of the germ be regarded as fully determined.

The sites of protein synthesis during early embryogenesis in birds and Amphibia have been studied by Prof. C. H. Waddington (Edinburgh) by the autoradiographic location of labelled amino-acids. Glycine 